\title{
Microstructure and phase transformation of Ni-Mn-Ga wires produced by the in rotating water melt-spinning technique \\ Xiaogang Sun ${ }^{1, a}$, Xiaomin Peng ${ }^{2, b}$ and Anru Wu ${ }^{3, c}$
}

\author{
College of Mechanical Engineering, Hunan Institute of Engineering, Xiangtan, 411104, China \\ Hunan Province Cooperative Innovation Center for Wind Powder Equipment and Energy Conversion, \\ Xiangtan, 411104, China \\ adavidsun@hnie.edu.cn, ${ }^{b} 70128 @$ hnie.edu.cn, ${ }^{c} 07115 @$ hnie.edu.cn
}

\begin{abstract}
Keywords: Ni-Mn-Ga; Shape memory alloys; In rotating water melt-spinning; Microstructure, Phase transformation.

Abstract. Shape memory $\mathrm{Ni}_{55} \mathrm{Mn}_{20.6} \mathrm{Ga}_{24.4}($ at $\%)$ wires of approximately $200 \mu \mathrm{m}$ in diameter were produced by the in rotating water melt-spinning technique (INROWASP). The microstructure of $\mathrm{Ni}-\mathrm{Mn}-\mathrm{Ga}$ wire was changed from dendritic-like into bamboo grains structure with only one crystal in the radial direction by annealing. Annealed wires exhibit sharp and well-defined transformation between austenite and martensite, $\mathrm{A}_{\mathrm{p}}$ to $82.4^{\circ} \mathrm{C}, \mathrm{M}_{\mathrm{p}}$ to $70.5^{\circ} \mathrm{C}$. The crystal structure of annealed wires presents non-moderated martensite and preferred orientation at (622).
\end{abstract}

\section{Introduction}

Ni-Mn-Ga ferromagnetic shape memory alloys (FSMAs) have triggered great interest for their high magnetic-field-induced strain (MFIS) up to 6\%-12\%, which are expected for actuators, sensors and dampers [1-3]. However, such large MFIS value is attained in single crystals but not in polycrystalline materials (less than of $1 \%$ of MFIS) due to constraints by grain boundaries on the motion of twin boundaries[4]. Moreover, bulk alloy material exhibits large current loss at high frequency [5]. To solve these problems, small size Ni-Mn-Ga alloys(e.g., wires, ribbons, films) and "consructs" from these structural elements (e.g., mats, laminates, textiles, foams and composites) are widely studied by various researchers [6-15]. These materials have presented superior properties by matching grain and sample sizes [15].

$\mathrm{Ni}-\mathrm{Mn}-\mathrm{Ga}$ wires or ribbons were usually fabricated by the Taylor-Ulitovsky method and melt spinning(and the related melt extraction method). The Taylor-Ulitovsky method often led to the trouble of removing glass sheath while the film-like shape wires fabricated by most of melt spun wires usually limit the application of $\mathrm{Ni}-\mathrm{Mn}-\mathrm{Ga}$ alloys, especially about $\mathrm{Ni}-\mathrm{Mn}-\mathrm{Ga} /$ polymer composites[6-15]. In rotating water melt-spinning (INROWASP) technique can achieve wires thin round shape [16]. Moreover, the microstructure and phase transformation of this thin round shape $\mathrm{Ni}-\mathrm{Mn}-\mathrm{Ga}$ wires have not been thoroughly investigated, and these are of great importance in the properties and application of $\mathrm{Ni}-\mathrm{Mn}-\mathrm{Ga}$ alloys. In the present article, $\mathrm{Ni}{ }_{55} \mathrm{Mn}_{20.6} \mathrm{Ga}_{24.4}$ wires, with $200 \mu \mathrm{m}$ diameter and thin round shape, were made by INROWASP technique and investigated in terms of microstructure and phase transformation.

\section{Experimental}

$\mathrm{Ni}_{55} \mathrm{Mn}_{20.6} \mathrm{Ga}_{24.4}$ (at\%) ferromagnetic memory alloy ingot was prepared by vacuum arc remelting (VAR) of high purity elements. $\mathrm{Ni}_{55} \mathrm{Mn}_{20.6} \mathrm{Ga}_{24}$ wires were obtained by INROWASP, which was similar to that previously reported in Refs $[10,16]$. The process was summarized briefly here. A jet of molten alloy is ejected through a nozzle $(200 \mu \mathrm{m}$ in diameter) into a rotating liquid cooling layer at a speed of $8 \mathrm{~m} / \mathrm{s}$. The ejection gas pressure of high purity Ar was $0.08 \mathrm{Mpa}$ and ejection angle was $40^{\circ}$. The nozzle tip-water distance was 3-5mm.

Pieces of $\mathrm{Ni}_{55} \mathrm{Mn}_{20.6} \mathrm{Ga}_{24}$ wires were sealed into a vacuum quartz ampoule and then the ampoule with wires were homogenized at $800{ }^{\circ} \mathrm{C}$ for 48 hours and quenched into cold water. The composition and microstructure of as-spun wires and annealed wires were determined by a SEM equipped with a 
thermal field emission gun (SEM, JEOL-6460). The transition temperatures of $\mathrm{Ni}_{55} \mathrm{Mn}_{20.6} \mathrm{Ga}_{24}$ samples were measured by differential scanning calorimetry (DSC, Perkin Elmer Pyris 1) at a heating/cooling rate of $10{ }^{\circ} \mathrm{C} / \mathrm{min}$. The crystal structures of $\mathrm{Ni}_{55} \mathrm{Mn}_{20.6} \mathrm{Ga}_{24}$ samples were determined by X-ray diffraction at room temperature (XRD, Dmax-2550V, Cu Ka, $40 \mathrm{KV}, 100 \mathrm{~mA})$.

\section{Results and discussion}

Fig. 1 describes the external form of as-spun $\mathrm{Ni}_{55} \mathrm{Mn}_{20.6} \mathrm{Ga}_{24}$ alloy wires. As shown in Fig.1, the wires shows their diameter of $\sim 200 \mu \mathrm{m}$ and length of 3-10 $\mathrm{cm}$. Because of the intrinsic brittleness of Ni-Mn-Ga alloys, $\mathrm{Ni}_{55} \mathrm{Mn}_{20.6} \mathrm{Ga}_{24}$ alloy wires are not long, quite different from other metal wires fabricated by the same INROWASP. The curve shape of $\mathrm{Ni}_{55} \mathrm{Mn}_{20.6} \mathrm{Ga}_{24}$ wires may be come from the wave of the water or not well optimized set of parameters.

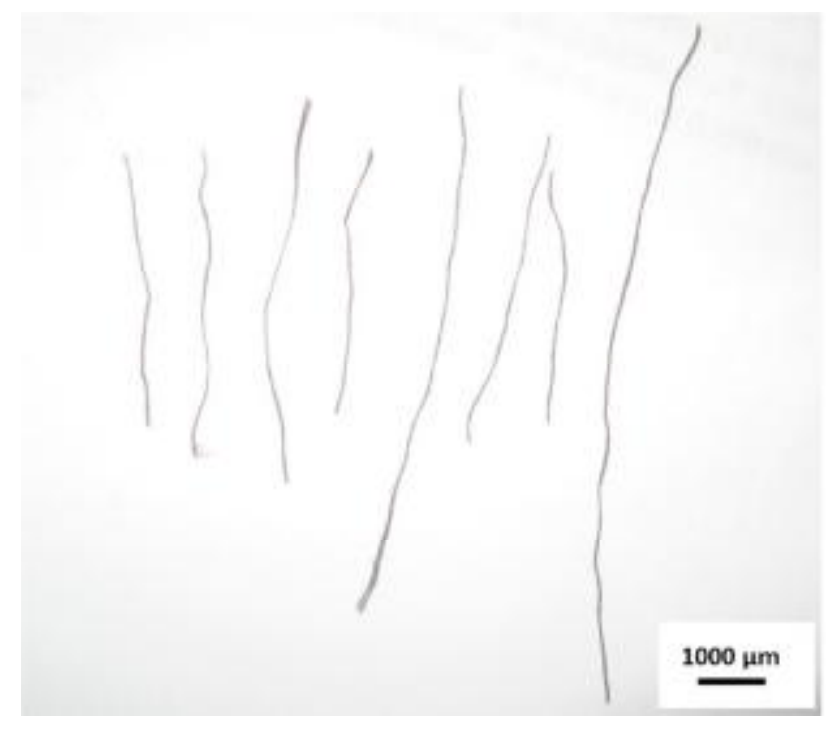

Fig.1 as-spun $\mathrm{Ni}_{55} \mathrm{Mn}_{20.6} \mathrm{Ga}_{24}$ alloy wires

Fig. 2 shows the microstructure of INROWASP wires before and after annealing along their longitudinal and radial directions. The diameter of $\mathrm{Ni}_{55} \mathrm{Mn}_{20.6} \mathrm{Ga}_{24}$ wires is about $200 \mu \mathrm{m}$. The structure of the as-spun wires are representative dendritic-like structures obtained in rapid solidified system, which is just like other results $[8,10]$. There are two kinds of microstructure, dendritic-like and cellular structure $[13,17]$, in the rapid solidified $\mathrm{Ni}_{55} \mathrm{Mn}_{20.6} \mathrm{Ga}_{24}$ wires. The difference of the microstructures comes from the difference of the composition and cooling speed [8, 17]. Further studies are needed to specify this issue in more details for better understanding. Additionally, it is interesting to find from the Fig.1(c) and (d) that the microstructure of $\mathrm{Ni}_{55} \mathrm{Mn}_{20.6} \mathrm{Ga}_{24}$ wires were transformed from dendritic-like structure into bamboo grains structure by annealing. This bamboo grains structure resembles single grains spanning the whole wire cross-section. Although similar bamboo grains structure had been previously reported in other rapidly solidified $\mathrm{Ni}_{55} \mathrm{Mn}_{20.6} \mathrm{Ga}_{24}$ alloys ( crucible melt extraction [9, 18], custom-built Taylor machine [12,14] ), there is little report about the transformation from dendrictic-like structure to bamboo grains structure by annealing for $\mathrm{Ni}_{55} \mathrm{Mn}_{20.6} \mathrm{Ga}_{24}$ wires. The special bamboo grains structure has two advantages. Firstly, for these individual grains, a large MFIS of Ni-Mn-Ga wires was measured in N. Scheerbaum paper [18]. Secondly, the special bamboo grains structure can be easily broken along the grain boundary into particles of single crystal while it is used to fabricate Ni-Mn-Ga/polymer composites [9]. Fig.2(c) and (d) show fully martensitic structure, indicating that the austenite/martensite transformation temperatures are above room temperature. It was confirmed in the following DSC and XRD results. 


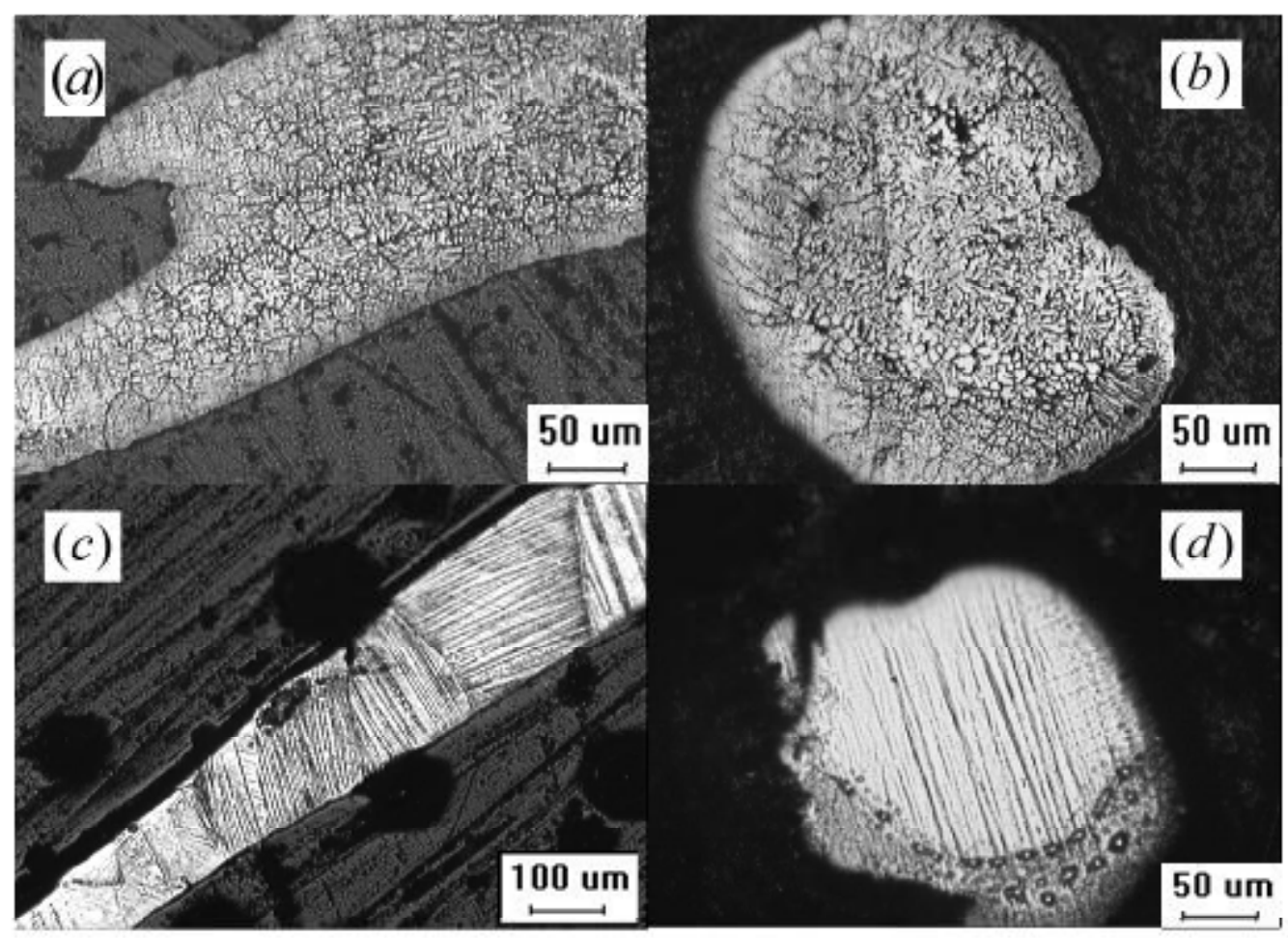

Fig.2 Optical images of $\mathrm{Ni}_{55} \mathrm{Mn}_{20.6} \mathrm{Ga}_{24.4}$ wire: (a),(b) as-spun, (c),(d) annealed (a),(c) longitudinal surlace (b), (d) cross surlace

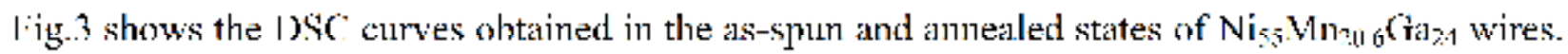
Compared to Fig.3(b), it was dillicult w lind the phase translormation in Fig.3(a). This phenomenon is different firom other researches' results as they found clear phease transformation from as-extracted wires or as-spun wires $[10,11,13]$. This might caused by the large intenal stress from large cooling speed in TNROWASP and the large compositional honengeneity. Further investigations of this istue are necded in more detail for better understanding. Annealed wircs exhibited a sharp and well-defincd transformation between austenite and martensite compared with the somewhal sneared transformation in the as-spun wircs, which was bccause heat treatment releases the internal stress and decredses the composiliomal homogeneily $[7,13\rceil$. ITowever, some exceptional peaks oceur on the martensitic transformation curve of the annealed wires. High transformation temperature can ensure

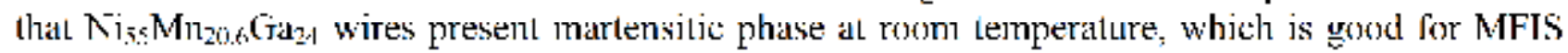
property of $\mathrm{Ni}-\mathrm{Mn}-\mathrm{Ca}$ polymer composite with these $\mathrm{Ni}-\mathrm{Mn}-\mathrm{Gia}$ wires used for fabricating composile.
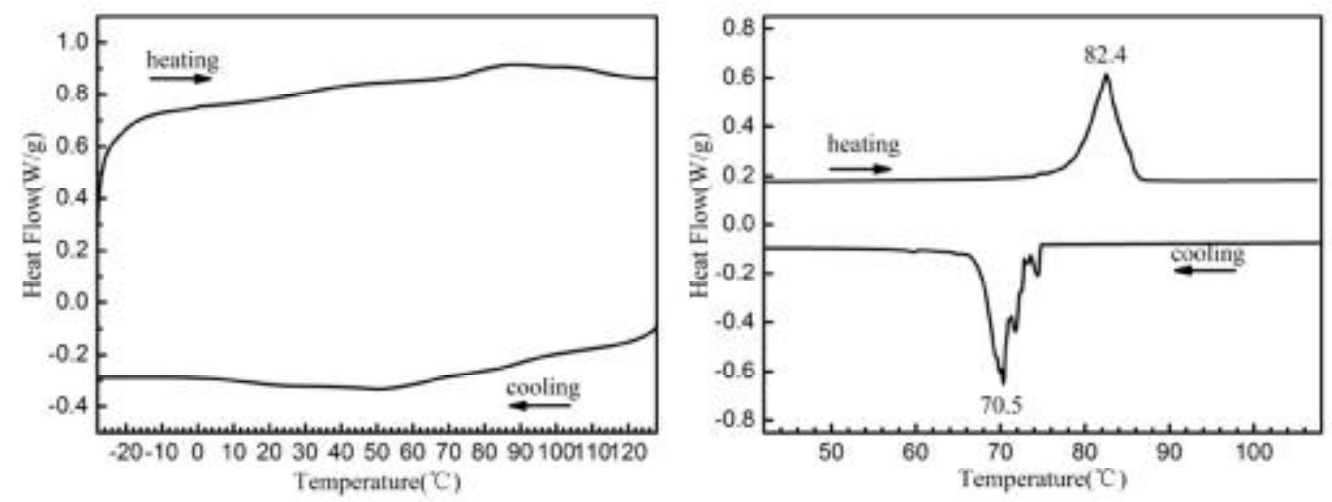

Fig.3 DSC curves of $\mathrm{Ni}_{55} \mathrm{Mn}_{20.6} \mathrm{Ga}_{24.4}$ wires: (a) as-spun, (b) annealed

In order to conlim the martensitic phase at room emperalure(Fig.1 and Fig.3), X-ray characterization of $\mathrm{Ni}_{55} \mathrm{Mn}_{20.6} \mathrm{Ga} 24.2$ powders and annealed wires were performed(see lig.4). 'l he

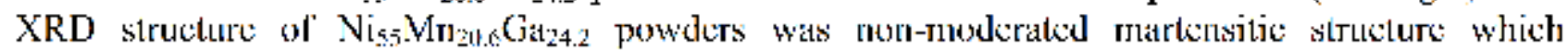


corresponded to Pons' investigations [19]. In addition, the intensities of (622) reflections in annealed wires is relatively higher than that observed in the powder, suggesting that the annealed wires of $\mathrm{Ni}_{55} \mathrm{Mn}_{20.6} \mathrm{Ga}_{24.2}$ have some preferential orientation. The similar observations of preferred orientation have been found in other researches [8,20].

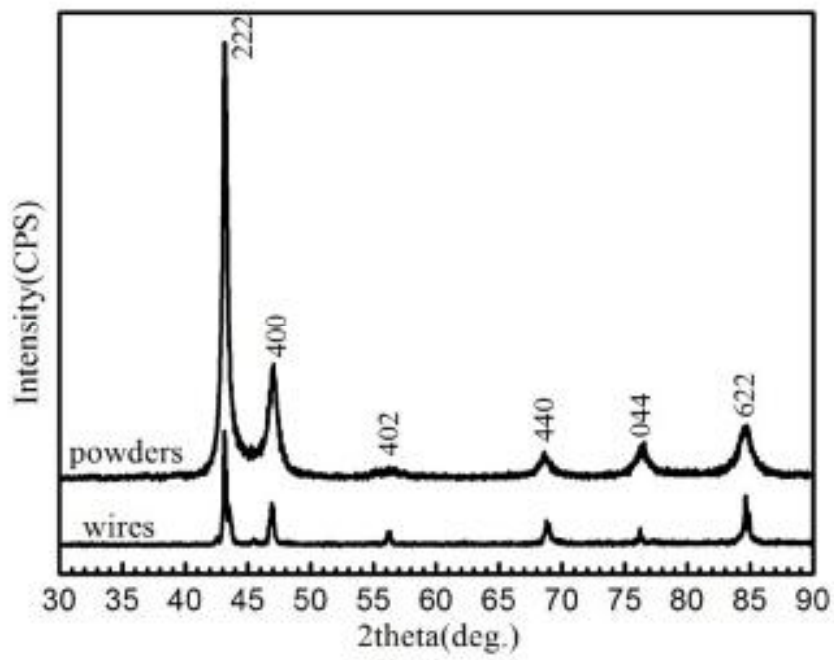

Fig.4 XRD analysis for $\mathrm{Ni}_{55} \mathrm{Mn}_{20.6} \mathrm{Ga}_{24.4}$ powders and wires

\section{Conclusions}

$\mathrm{Ni}_{55} \mathrm{Mn}_{20.6} \mathrm{Ga}_{24.4}($ at\% $)$ wires were fabricated by the in rotating water melt-spinning technique(INROWASP). As-spun wires exhibits dendritic-like microstructure while bamboo grain microstructure is observed in the annealed wires. The peak temperatures of phase transformations of annealed wires are at $82.4^{\circ} \mathrm{C}$ and $70.5^{\circ} \mathrm{C}$, corresponding to martensitic phase to austenitic phase, austenitic phase to martensitic phase, respectively. The crystal structure of annealed wires presents non-moderated martensite and preferred orientation at (622).

\section{Acknowledgements}

This work was financially supported by National Natural Science Foundation of China (11572124, 51671085) and Scientific Research Fund of Hunan Provincial Education Department (14B042).

\section{References}

[1] S.J. Murray, M. Marioni, S.M. Allen, R.C. O'Handley, T.A. Lograsso, 6\% magnetic-field-induced strain by twin-boundary motion in ferromagnetic Ni-Mn-Ga, Applied Physics Letters, vol. 77 (2000), p.886

[2] A. Sozinov, A.A. Likhachev, N. Lanska, K. Ullakko, Giant magnetic-field-induced strain in NiMnGa seven-layered martensitic phase, Applied Physics Letters, vol. 80 (2002), p.1746

[3] A. Sozinov, N. Lanska, A. Soroka, W. Zou, 12\% magnetic field-induced strain in Ni-Mn-Ga-based non-modulated martensite, Applied Physics Letters, (2013), p.102

[4] U. Gaitzsch, M. Poetschke, S. Roth, B. Rellinghaus, L. Schultz, A 1\% magnetostrain in polycrystalline 5M Ni-Mn-Ga, Acta Materialia, vol.57 (2009), p.365

[5] R.J. Ong, J.T. Dawley and P.G. Clem: submitted to Journal of Materials Research (2003) M.A. Marioni, R.C. O'Handley, S.M. Allen, Pulsed magnetic field-induced actuation of Ni-Mn-Ga single crystals, Applied Physics Letters, vol. 83 (2003), p.3966 
[6] R. Varga, T. Ryba, Z. Vargova, K. Saksl, V. Zhukova, A. Zhukov, Magnetic and structural properties of Ni-Mn-Ga Heusler-type microwires, Scripta Materialia, vol.65 (2011), p.703

[7] O. Heczko, P. Svec, D. Janickovic, K. Ullakko, Magnetic properties of Ni-Mn-Ga ribbon prepared by rapid solidification, Ieee Transactions on Magnetics, vol. 38 (2002), p.2841

[8] N.V.R. Rao, R. Gopalan, M.M. Raja, J.A. Chelvane, B. Majumdar, V. Chandrasekaran, Magneto-structural transformation studies in melt-spun Ni-Mn-Ga ribbons, Scripta Materialia, vol.56 (2007), p.405.

[9] N. Scheerbaum, D. Hinz, O. Gutfleisch, K.H. Mueller, L. Schultz, Textured polymer bonded composites with Ni-Mn-Ga magnetic shape memory particles, Acta Materialia, vol.55 (2007), p. 2707

[10] C. Gomez-Polo, J.I. Perez-Landazabal, V. Recarte, V. Sanchez-Alarcos, G. Badini-Confalonieri, M. Vazquez, Ni-Mn-Ga ferromagnetic shape memory wires, Journal of Applied Physics, (2010), p.107

[11] A. Zhukov, V. Rodionova, M. Ilyn, A.M. Aliev, R. Varga, S. Michalik, A. Aronin, G. Abrosimova, A. Kiselev, M. Ipatov, V. Zhukova, Magnetic properties and magnetocaloric effect in Heusler-type glass-coated NiMnGa microwires, Journal of Alloys and Compounds, vol.575 (2013), p73

[12]Z. Peiqi, N.J. Kucza, C.L. Patrick, P. Mullner, D.C. Dunand, Mechanical and magnetic behavior of oligocrystalline Ni-Mn-Ga microwires, Journal of Alloys and Compounds, vol.624 (2015),p. 226

[13]M.F. Qian, X.X. Zhang, L.S. Wei, L. Geng, H.X. Peng, Effect of chemical ordering annealing on martensitic transformation and superelasticity in polycrystalline Ni-Mn-Ga microwires, Journal of Alloys and Compounds, vol.645 (2015), p.335

[14]Z.L. Wang, P. Zheng, Z.H. Nie, Y. Ren, Y.D. Wang, P. Muellner, D.C. Dunand, Superelasticity by reversible variants reorientation in a $\mathrm{Ni}-\mathrm{Mn}-\mathrm{Ga}$ microwire with bamboo grains, Acta Materialia, vol.99 (2015), p. 373

[15] D.C. Dunand, P. Muellner, Size Effects on Magnetic Actuation in Ni-Mn-Ga Shape-Memory Alloys, Advanced Materials, vol.23 (2011), p. 216

[16] P. Ochin, A. Dezellus, P. Plaindoux, J. Pons, P. Vermaut, R. Portier, E. Cesari, Shape memory thin round wires produced by the in rotating water melt-spinning technique, Acta Materialia, vol.54 (2006), p.1877

[17]L. Yanfen, Z. Xuexi, X. Dawei, Q. Mingfang, S. Hongxian, W. Huan, L. Jingshun, S. Jianfei, Shape memory effects of $\mathrm{Ni} 49.7 \mathrm{Mn} 25.0 \mathrm{Ga} 19.8 \mathrm{Fe} 5.5$ microwires prepared by rapid solidification, Physica Status Solidi A - Applications and Materials Science, vol.211 (2014), p. 2532

[18]N. Scheerbaum, O. Heczko, J. Liu, D. Hinz, L. Schultz, O. Gutfleisch, Magnetic field-induced twin boundary motion in polycrystalline Ni-Mn-Ga fibres, New Journal of Physics, (2008), p. 10

[19] J. Pons, V.A. Chernenko, R. Santamarta, E. Cesari, Crystal structure of martensitic phases in Ni-Mn-Ga shape memory alloys, Acta Materialia, vol.48 (2000), p.3027

[20]F. Albertini, S. Besseghini, A. Paoluzi, L. Pareti, M. Pasquale, F. Passaretti, C.P. Sasso, A. Stantero, E. Villa, Structural, magnetic and anisotropic properties of Ni2MnGa melt-spun ribbons, Journal of Magnetism and Magnetic Materials, 242-245, Part 2 (2002), p.1421 